\title{
ERRATA
}

Artigo originalmente publicado com data de aprovação errada

\section{Número de repetições para a comparação de cultivares de milho}

\author{
Number of replications for the comparison in corn cultivars
}

Alberto Cargnelutti Filho ${ }^{\text {I* }}$ Lindolfo Storck ${ }^{\mathrm{I}}$ José Paulo Guadagnin $^{\mathrm{II}}$

Para html ou PDF, acesse, respectivamente:

http://www.scielo.br/scielo.php?script=sci_arttext\&pid=S0103-84782010000500004\&lng=en\&nrm=iso\&tlng=pt ou http://www.scielo.br/pdf/cr/v40n5/a568cr2425.pdf

We sugest that subscribers photocpy this correction and insert the copy at the appropriate place where the article originally appeared. Sugerimos que uma fotocópia das correções seja inserida na página correta onde o artigo apareceu originalmente.

'Departamento de Fitotecnia, Centro de Ciências Rurais (CCR), Universidade Federal de Santa Maria (UFSM), 97105-900, Santa Maria, RS, Brasil. E-mail: cargnelutti@pq.cnpq.br. *Autor para correspondência.

"Fundação Estadual de Pesquisa Agropecuária (FEPAGRO), Porto Alegre, RS, Brasil. 